\title{
Cloud Strategy Development for Medium and Small Business
}

\author{
Dmitrijs Bolozdiña ${ }^{1}$, Rūta Pirta-Dreimane ${ }^{2}$, Andrejs Romānovs ${ }^{3}$ \\ ${ }^{1-3}$ Riga Technical University, Riga, Latvia
}

\begin{abstract}
The authors, within the present research, aim at making more extensive use of ICT by developing a cloud service strategy that will contribute to the dissemination of knowledge and help in deployment. Companies will be able to assess their readiness to implement cloud services, explore the approaches, benefits and disadvantages of cloud services. Cloud services are a solution to most SMEs, regardless of size, activity or existing ICT infrastructure. Smaller companies can implement SaaS-type solutions, but companies with advanced ICT infrastructure can focus on IaaS and PaaS-type solutions.
\end{abstract}

Keywords - Capability maturity model, change management, computer network virtualization, platform virtualization.

\section{INTRODUCTION}

The study has been conducted during the COVID-19 pandemic and an emergency state has been declared. The state of emergency applies to all organisations and institutions, so it is required to keep social distancing and preferably stay at home. People are forced to withdraw from services provided by companies, and this situation affects economy and the existence of companies. The above factors have led to an increased need for the deployment of information and communication technologies (hereinafter - ICT) to continue providing services. In this context, companies must be able to work remotely and provide services electronically through the global web. Ecommerce and remote operation require adequate infrastructure so it should ensure all functional and non-functional requirements for different tasks, including the establishment of communication, the registration and processing of services or orders, in parallel ensuring safety, accessibility, ease of use and automation. Cloud strategy contains assessment of current situation and provides improvement plan.

\section{ANALYSIS OF AN EXISTING SITUATION}

Scientific articles forecast widespread use of the Internet [1]. Newer technologies, including cloud services, can be used to perform different tasks, depending on the context and considering diversity of business areas so there is no single onefits-all solution. Needs may vary from size, type of activity, industry, and other factors.

Latvian small and medium enterprises (hereinafter - SME) use $20 \%$ less cloud computing services than large companies (see Table I). This trend is also observed in the reports of the European institutions. Quote from [2]: "The Latvian business sector is still lagging behind the EU average, not only in terms of digital technology integration, but also in terms of human capital. Almost half of the population still lacks basic digital skills and the number of ICT professionals prepared is lagging behind the growing demand in the labour market."

TABLE I

Cloud Computing USAGE By Company Size

\begin{tabular}{|l|r|r|}
\hline $\begin{array}{l}\text { Enterprises using cloud computing services } \\
\text { (as \% of the total number of enterprises in the } \\
\text { corresponding group) [3] }\end{array}$ & $\begin{array}{c}\text { Cloud } \\
\text { computing } \\
\text { services }\end{array}$ & $\begin{array}{l}\text { Paid cloud } \\
\text { computing } \\
\text { services }\end{array}$ \\
\hline .. with a number of employees of 10-49 & 21.9 & 12.7 \\
\hline .. with a number of employees of 50-249 & 30.1 & 20.9 \\
\hline .. with a number of employees of 250 or more & 50.5 & 38.5 \\
\hline
\end{tabular}

In the light of the results outlined above, the authors conclude that the subject of the study is justified. The strategy will be addressed to SMEs in order to promote wider uptake of ICT and raising the knowledge levels for these entrepreneurs.

\section{ASSESSING SME READINESS FOR CLOUD SERVICES}

The development of the strategy requires an exploration of an existing SME IT infrastructure. Companies in this group work in a wide variety of sectors, ranging from retail, accommodation or catering services to the electricity, gas, heating and air-conditioning sectors; therefore, the development of overall characteristics is not a trivial task. In order to carry out this task, it is necessary to assess the undertakings in the above sector and to process as much information as possible. Referring to [4], small businesses buy fewer materials and services, and this also covered ICT. With fewer people, the number of decision-makers is declining, and everything depends on a certain level of knowledge of the head of the company [5]. Small businesses have fewer financial resources [6]. Factors influencing the views of businesses in ICT deployment are summarised in Table II. Non-motivating factors become stronger with a reduction in the number of company employees.

The impact of the crisis has narrowed the possibility of obtaining the necessary information or conducting surveys, so the database of the Central Statistical Bureau of Latvia has been chosen as the main source of information. A total of 28 reports have been prepared and used for overview creation and analysis. 
TABLE II

FACTORS AFFECTING ICT DEPLOYMENT

\begin{tabular}{|c|c|c|}
\hline Opinion & Motivating & Non-motivating \\
\hline Infrastructure and its components are ageing and require renewal & & $\mathrm{x}$ \\
\hline $\begin{array}{l}\text { The transfer of ICT support functions to the external service provider contributes to the } \\
\text { dependency on the external service provider }\end{array}$ & & $\mathrm{x}$ \\
\hline $\begin{array}{l}\text { Preference for ICT processes that improve efficiency and increase returns than add value to } \\
\text { existing processes }\end{array}$ & & $\mathrm{x}$ \\
\hline Companies introduce ICT motivated by mandatory national requirements & $\mathrm{x}$ & \\
\hline $\begin{array}{l}\text { Owners and managers do not have the expertise to understand the potential benefits of ICT } \\
\text { investment }\end{array}$ & & $\mathrm{x}$ \\
\hline Lack of information on support mechanisms from national and regional authorities & & $\mathrm{x}$ \\
\hline Not enough knowledge and time for ICT assessment & & $\mathrm{x}$ \\
\hline Not enough knowledge and time for ICT deployment & & $\mathrm{x}$ \\
\hline Insufficient free financial resources & & $\mathrm{x}$ \\
\hline $\begin{array}{l}\text { If owners and managers are not involved and there is no understanding of ICT for the } \\
\text { company, the professional competencies of external consultants have a high } \\
\text { impact/importance }\end{array}$ & & $\mathrm{x}$ \\
\hline $\begin{array}{l}\text { Traditional ICT service management processes are based on a standardised and ad-hoc } \\
\text { approach }\end{array}$ & & $\mathrm{x}$ \\
\hline $\begin{array}{l}\text { Outsourcing providers cannot provide full support for ICT infrastructure because they are } \\
\text { familiar with one specialised service }\end{array}$ & & $\mathrm{x}$ \\
\hline High implementation costs & & $\mathrm{x}$ \\
\hline Disproportionate return requirements & & $\mathrm{x}$ \\
\hline Fear of potential disclosure of business secrets & & $\mathrm{x}$ \\
\hline Restrictions on existing ICT solutions & & $\mathrm{x}$ \\
\hline $\begin{array}{l}\text { Purchased applications are ageing and do not introduce new functions and do not support } \\
\text { compatibility with other solutions }\end{array}$ & & $\mathrm{x}$ \\
\hline Improved operational efficiency & $\mathrm{x}$ & \\
\hline Improved customer service & $\mathrm{x}$ & \\
\hline Competition with other companies & $\mathrm{x}$ & \\
\hline Improving employee satisfaction & $\mathrm{x}$ & \\
\hline Improving communication with suppliers & $\mathrm{x}$ & \\
\hline Promoting cooperation in companies & $\mathrm{x}$ & \\
\hline Customer-requested services & $\mathrm{x}$ & \\
\hline The nature of the business is linked to the use of ICT & $\mathrm{x}$ & \\
\hline Changes in industry contribute to the need to implement ICT & $\mathrm{x}$ & \\
\hline ICT outsourcing providers and cloud solutions offer a chance to try prepayment & $\mathrm{x}$ & \\
\hline Global digitization contributes to communication and availability through the Internet & $\mathrm{x}$ & \\
\hline $\begin{array}{l}\text { Companies with advanced maturity and Internet presence are better prepared for the } \\
\text { implementation and development of new processes }\end{array}$ & $\mathrm{x}$ & \\
\hline Reducing ICT costs & $\mathrm{x}$ & \\
\hline Improved service range and quality & $\mathrm{x}$ & \\
\hline Decreased service delivery time & $\mathrm{x}$ & \\
\hline ICT provides opportunities to find suppliers & $\mathrm{x}$ & \\
\hline Gaining insight through ICT solutions & $\mathrm{x}$ & \\
\hline
\end{tabular}

Based on the report analysis and the above findings, different levels of infrastructure complexity can be identified. In order to address the recommendations for improvement and ICT deployment, it is necessary to merge companies into sub-groups with similar infrastructure.

\subsection{ICT by Size}

ICT is applied more along with an increase in the number of physical devices in the company. Enterprise devices and their operating systems, applications and application platforms, as well as a network that combines all infrastructure in one must be maintained, secured and backed up.

Large business structures tend to be complex, and training of young employees to carry out job responsibilities involves the presence and maintenance of training materials. Apart from training materials, the undertaking must ensure the circulation of working instructions, internal documents and financial reports.
An analysis of company size indicates that there is a relationship between the size of the company and IT infrastructure, but it is not obvious. It is not possible to identify a set of solutions that are specific to company by matter of size.

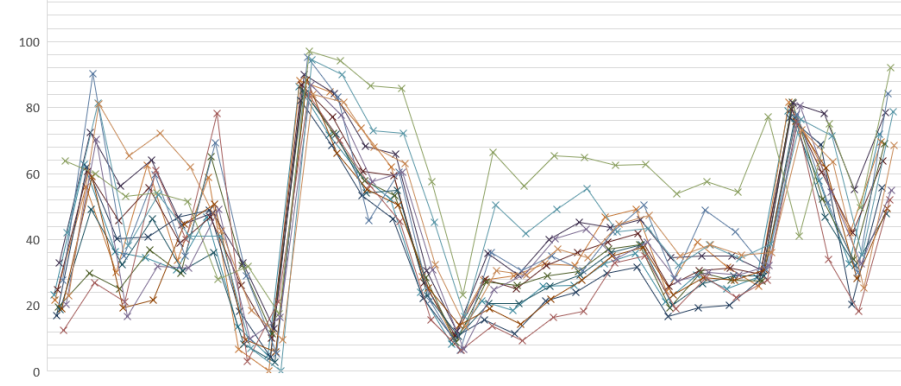

Fig. 1. ICT adoption by industry. Each line represents industry and enterprises using specific ICT (as \% of the total number of enterprises in the corresponding group). ICT used in the analysis is the ICT listed by the Central Statistical Bureau of Latvia [3]. 


\section{ICT BY INDUSTRY}

Report analysis allows concluding that, regardless of the sector, businesses use ICT. The aggregated data on industries and technologies are available in Fig. 1. Intersection and concentration of curves mean a similar percentage distribution.

The study shows that universal use is limited to the Internet, e-mail and office software, but common trends are only observed for companies in "old" industries. These companies are subject to national regulatory rules. Other SMEs do not use strategic or tactical management applications [7]. Similar results are also shown by central statistical management data (see Fig. 1).

An analysis of the business sector leads to the conclusion that the relationship between the sector and the technologies applied is not apparent. To address problems and offer cloud solutions, it is necessary to divide companies into groups with similar infrastructure. The authors propose classifying companies according to the infrastructure elements applied.

\section{A. Infrastructure Building Blocks}

With the increase in the number of employees, the number and complexity of technological solutions contributing to the expansion of infrastructure also increase. Infrastructure is all the hardware, software, networks, equipment, etc. needed to develop, shift, monitor, control or support IT services (ITILv3). The infrastructure is hidden from end users, a technological infrastructure covers the invisible protocol, network and programs that combine the enterprise's computing capabilities and provide efficient data flows (Technology Governance Board Definition of Information Technology Infrastructure). The infrastructure components are compiled in the form of a dime approach from EA building practices and listed in Table III. In the cloud, it is possible to deploy previously mentioned infrastructure components with some restrictions [8].

TABLE III

ICT INFRASTRUCTURE [13], [14], [15]

\begin{tabular}{|c|c|c|c|}
\hline $\begin{array}{l}\text { Business process } \\
\text { and information }\end{array}$ & Software & Application platform & Infrastructure \\
\hline $\begin{array}{l}\text { Basic business } \\
\text { functions } \\
\text { Profit-making } \\
\text { processes and } \\
\text { functions } \\
\text { Support functions } \\
\text { and processes } \\
\text { needed to provide } \\
\text { basic business } \\
\text { processes } \\
\text { For example, } \\
\text { accounting, } \\
\text { business planning, } \\
\text { personnel } \\
\text { management, } \\
\text { customer support }\end{array}$ & $\begin{array}{l}\text { Typical apps used on } \\
\text { computers. For } \\
\text { example, a web } \\
\text { browser, word } \\
\text { processing programs. } \\
\text { Applications hosted on } \\
\text { servers, and most of } \\
\text { the companies use } \\
\text { them. For example, e- } \\
\text { mail apps, portals, } \\
\text { collaboration tools. } \\
\text { Business-specific } \\
\text { applications are apps } \\
\text { that are tailored } \\
\text { specifically. For } \\
\text { example, Customer } \\
\text { Relationship } \\
\text { Management } \\
\text { Programs (CRM), } \\
\text { Enterprise Resource } \\
\text { Planning (ERP). }\end{array}$ & $\begin{array}{l}\text { Front-end servers are usually web servers. } \\
\text { Enable interaction with applications by } \\
\text { presenting application screens in web } \\
\text { browsers. For example, an Apache HTTP } \\
\text { server, Microsoft Information Services - IIS. } \\
\text { Application servers act as containers running } \\
\text { an actual program. For example, Java or } \\
\text {.NET servers for application systems. } \\
\text { WebSphere, Apache Tomcat, Red Hat } \\
\text { JBoss. } \\
\text { Connection servers. Include FTP servers, } \\
\text { ETL, ESB. For example, MS BizTalk, } \\
\text { TIBCO service bus, IBM MQ, SAP } \\
\text { NetWeaver PI. } \\
\text { Databases, also known as database } \\
\text { management systems (DBMS), allow storing } \\
\text { and retrieving structured data. For example, } \\
\text { Oracle RDBMS, IBM DB2, MS SQL } \\
\text { Server, Postgree, MySQL. }\end{array}$ & $\begin{array}{l}\text { End-user devices used by users to work with applications. } \\
\text { For example, PCs, laptops, thin customers, mobile devices } \\
\text { and printers. } \\
\text { Operator systems are a set of programs that manage the } \\
\text { internal operation of a computer: its memory, processors, } \\
\text { devices, and file system. } \\
\text { Computing capabilities are physical and virtual computers } \\
\text { in a data centre called servers. } \\
\text { Storage is a system where data are stored. For example, } \\
\text { hard drives, tapes, direct-attached storage (DAS), } \\
\text { networked storage (NAS) and storage area networks } \\
\text { (SAN). } \\
\text { Networking connects all components. This block will } \\
\text { include routers, switches, firewalls, WAN, LAN, VPN, } \\
\text { network applications. } \\
\text { Data centres are places where most infrastructure hardware } \\
\text { is housed. These include equipment such as UPS, heating, } \\
\text { ventilation and air conditioning (HVAC). }\end{array}$ \\
\hline
\end{tabular}

\section{Cloud SERVICES}

The main motivation for the use of cloud services is efficient costs, more efficient memory use, scalability, resistance to errors, data security, frugal management, mobility, emergency recovery, control, and competitiveness [9], [10]. Research shows that SMEs are the most suited for SaaS cloud services with a public cloud. Of course, before the implementation, changes to the software and network structure are required [11].
The SaaS concept provides independent functioning of software and components that can be identically achieved with service-oriented architecture and micro-service architecture [12]. Research shows that SaaS is more reliable in terms of security than locally deployed infrastructure [9]. The advantages and disadvantages of SaaS and the use of ERP systems for SMEs are described in [9].The company may choose software and migrate it to the cloud (SaaS), but if the developer does not foresee such functionality, it will be necessary to rebuild it. 
The deployment of cloud services plays a major role in cooperation with service providers. Each of them has its own platform-specific protocols, standards and tools that inevitably lead to deep integration and an inability to easily opt out or change the service (vendor lock-in), which is also a perceived concern in the deployment of cloud services [17]. The selection criteria for a public cloud service provider are explained in [18], [17]. Concerning an inability to find an appropriate public cloud service provider, the solution would be to implement a private cloud [19].

\section{MigRATION APPROACHES}

ICT solutions can be replaced by one or more components of cloud services, partially migrated one or more layers of application, or a set of architectural components, or migrating the entire service infrastructure (application encapsulated VM and launched on cloud service) and converting to cloud-based services (complete processing of an application using cloud services) [20]. In the case of cloud service implementation, the cloud service model, IaaS, PaaS or SaaS, should be identified depending on the technology deployed. There are wide-ranging models in the literature that help each of the models mentioned above in migration. Cloud providers are trying to ease migration and develop special tools and approaches. Microsoft offers four typical scenarios in operating system or software applications for migration such as rehost, revise, refactor and replacelretire.

A senior cloud service market participant, Amazon offers a broader migration breakdown called the Six "R" approach (6 Strategies for Migrating Applications to the Cloud / AWS [21].

The developers of the paid software are keeping pace with trends and offer their own solutions and tools for cloud migration. Without major cloud service providers and software developers, the tools for facilitating migration are also developed by scientists [20]. The following tools for scientific development have been found in the literature:

- automated migration tool with artificial intelligence [22];

- application software migration guide describing risks in deployment [23];

- application evaluation tools [24];

- assessment of the migration readiness of cloud service providers and software has developed a decision support system for the migration of cloud services. Cloud decision support framework, CloudDSF [21];

- cloud orchestration solutions [25];

- automated migration of virtual machines from local to cloud environment [26];

- HM migration, security context, assessment framework [27];

- a study on problems and solutions for determining HM addictions [19];

- real-time VM migration solution [17];

- real-time migration solution for reduced virtual machines or without maintenance time [28];

- web tool for migration of 3-D database [29].

Successful deployment of technology requires appropriate business processes. Without application, network, security and memory reconfiguration, it is not possible to achieve interaction among components. The company must be ready for serviceoriented or microservice architecture [11], [18], [30]-[32].

The interaction among the various infrastructure components requires the implementation of a company service bus [33].

Cloud services also include the use of other technologies: a connectivity service proxy or connection service adapter [34], an identity and access management system [35], an interface API, load balancers and gateways [36].

Summarising all the above, it can be concluded that cloud services can replace an existing infrastructure component, which exactly should be assessed during functional or nonfunctional requirement review.

\section{ASSESSING ICT MATURITY LEVEL OF SMES}

The implementation of e-commerce is critical to businesses. The stages of the e-commerce deployment are discussed in [37]. In scientific literature and practice, the capability maturity model (hereinafter referred to as CMM) is used to determine the level of technological maturity of a software development company [38]. With reference to the material described above, the authors propose a new method for assessing the maturity level of companies, available in Table IV and based on [38], [39], [37], [40], [41].

The changes in the table do not only affect IT infrastructure, but also the interaction among processes or services. A scenario where a change in service interaction was not predicted could lead to a system unavailability or limited functionality. Successful technology implementation requires a structured approach. A structured approach to the introduction of information systems is called change management.

\section{CHANGE MANAGEMENT}

Given the development of a strategy for ICT deployment during the study, it is necessary to apply a change management approach. The term of Information Technology Management includes international standards like ITIL, COBIT, Val-IT, CMM, ISO/IEC 27001 and others [42], [43], [44].

The authors' standard selection for change management is based on the ability to apply re-usable building blocks. Reusable blocks should display information on ICT solutions without going into related business processes, as business processes tend to differ considering SME business area diversity. EA has a comprehensive approach to harmonizing and reflecting company processes, strategy and IT [45]. The enterprise architecture management standards are described in TOGAF and ISO 42010 [46], [43]. TOGAF is the global standard for the enterprise architecture. It explains very well what EA should be and what it should do [47]. Thus, the view of the Technology Architecture (hereinafter "TA") should be defined as a cross-layered view, which includes elements from all layers of architecture. Since a strategy is addressed to a large group of companies, abstract references to AA and TA models are offered. Viewpoints and views are suitable for this purpose [48]. The viewpoints are based on ISO/IEC 42010: 2007, ISO Standard Reference Model for Open Distributed Processing (RM-ODP), TOGAF [49]. 
TABLE IV

ICT MATURITY LEVEL ASSESSMENT

\begin{tabular}{|c|c|c|}
\hline \multicolumn{3}{|c|}{ Evolutionary levels } \\
\hline \multicolumn{2}{|c|}{ Single user technology usage } & Organisation ICT integration \\
\hline \multicolumn{3}{|c|}{ Technology control } \\
\hline 1. Initial & 2. Disciplined & 3. Defined standard \\
\hline $\begin{array}{l}\text { The quality of work depends on the skills of } \\
\text { the PC user. }\end{array}$ & $\begin{array}{l}\text { Control of basic software management. } \\
\text { Software usage standards are defined and met. }\end{array}$ & $\begin{array}{c}\text { Standard software management processes are } \\
\text { documented and integrated. }\end{array}$ \\
\hline The quality of work is unpredictable. & Software functionality and costs are tracked and monitored. & $\begin{array}{l}\text { Appropriate training programmes for } \\
\text { employees to use software. }\end{array}$ \\
\hline $\begin{array}{l}\text { Employees with a separate computer and } \\
\text { productivity software. One can use a } \\
\text { private computer for business purposes. } \\
\text { One has the Internet connection and a } \\
\text { private e-mail account. }\end{array}$ & $\begin{array}{l}\text { Organisations with their own business card type homepage } \\
\text { or social network profile. The company respects security } \\
\text { measures and regularly updates the software to the latest } \\
\text { version. All software is licensed and regularly restored. The } \\
\text { company defines programs that are available to employees. } \\
\text { Employees' computers have strict passwords. }\end{array}$ & $\begin{array}{l}\text { Computers are joined into the network. } \\
\text { Security standards are defined. Employees } \\
\text { work together using applications and data } \\
\text { hosted on the network. Possible use of an } \\
\text { intranet. Workers are trained to work with } \\
\text { ICT solutions. }\end{array}$ \\
\hline
\end{tabular}

\begin{tabular}{|c|c|c|c|}
\hline \multicolumn{4}{|c|}{ Revolution levels } \\
\hline $\begin{array}{c}\text { Business process } \\
\text { adjustment }\end{array}$ & Business network adjustment & \multicolumn{2}{|c|}{ Redefined business scope } \\
\hline \multicolumn{4}{|c|}{ Data control } \\
\hline \multicolumn{2}{|c|}{$\begin{array}{l}\text { 1. Managed and predictable } \\
\text { tandards are assessed for all important activities in all } \\
\text { services. }\end{array}$} & \multicolumn{2}{|c|}{ 2. Continuous improvement } \\
\hline \multirow{2}{*}{\multicolumn{2}{|c|}{$\begin{array}{l}\begin{array}{l}\text { Quantitative measurement standards are available to evaluate business processes } \\
\text { and services. }\end{array} \\
\begin{array}{c}\text { Serious differences in process performance can be distinguished from random } \\
\text { variations. }\end{array}\end{array}$}} & \multicolumn{2}{|c|}{$\begin{array}{l}\text { Focus on improving the organisation-wide continuous process. } \\
\text { There are available means to proactively identify and strengthen } \\
\text { process gaps. Software engineering innovations are identified and } \\
\text { accepted by all organisational units. }\end{array}$} \\
\hline & & & \\
\hline $\begin{array}{l}\text { An organisation with a home page that } \\
\text { provides a two-way flow of information. The } \\
\text { data used in the application or home page are } \\
\text { stored in a structured way and available with } \\
\text { structured queries. Configuration provides an } \\
\text { application platform hosted on servers. The } \\
\text { company is high-speed connected to the } \\
\text { Internet. }\end{array}$ & $\begin{array}{l}\text { The organisation uses unified } \\
\text { application software that } \\
\text { supports a variety of business } \\
\text { processes, including purchase, } \\
\text { sale, accounting, production, } \\
\text { etc., thereby promoting the } \\
\text { integration of information and } \\
\text { division within the company. }\end{array}$ & $\begin{array}{l}\text { The organisation provides a secure } \\
\text { network and web server that supports } \\
\text { financial transactions and the } \\
\text { processing of payment data. }\end{array}$ & $\begin{array}{l}\text { The organisation ensures that } \\
\text { all business processes } \\
\text { involve the storage of } \\
\text { information. }\end{array}$ \\
\hline
\end{tabular}

\section{CLASSIFICATION AND DESCRIPTION OF VIEWPOINTS}

The authors' viewpoint taxonomy is based on the United States EA Model (FEAF) for Application Taxonomy (Federal Enterprise Architecture Framework Version 2, 2013). For technology architecture, open group EA TRM, Application Platform Taxonomy has been chosen (Foundation Architecture:
Technical Reference Model, 2006). The selection of these taxonomies is based on their ability to display ICT mentioned in the previous sections.

This viewpoint is used at the beginning of the design creation to present the common idea. This will display attributes from BA, AA, TA levels. In EA's standard and ArchiMate notation, 
it is called a multi-layered view [48]. It is designed for software engineers, process owners and employees.

The infrastructure viewpoint is used to display cloud service place in the enterprise infrastructure. View allows reflecting local infrastructure components that can be replaced by cloud services.

The above information provides an opportunity to group SMEs based on the ICT used and to reflect common components. Companies will be merged according to the classification in Table IV. Using the TOGAF standard and ArchiMate modelling language, the results of the classification are reflected.

\section{A. Group-Original}

The group foresees a minimal use of computer and technology. Possible job scenarios include occasional computer use. The restriction of the first group is the absence of safety management principles. Companies in this group do not update the software version and do not use strict passwords that also distinguish these companies from Group 2 members. Undertakings which do not meet the criteria of Group 2 shall be members of Group 1.

This view (see Fig. 2) involves the use of the following software services:

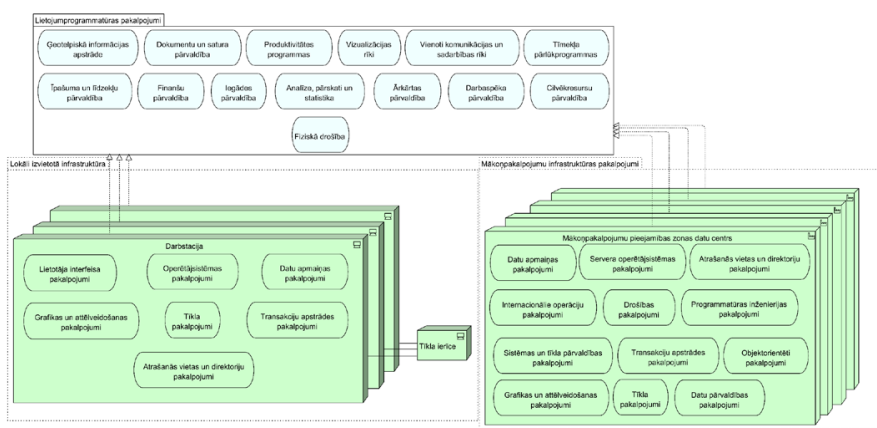

Fig. 2. Application and technology architecture viewpoint of Group A. Application service and technology service taxonomies are based on FEAF and TA TRM.

geospatial information processing, document and content management, productivity applications, visualization tools, common communication and cooperation tools, web browsers, property management, financial management, purchase management, analysis, reporting and statistics, emergency management, labour management, human resources management, physical security.

Infrastructure services use services such as: operating system services, data exchange services, network services, user interface services, graphics and imaging services, location sites and directory services.

The enterprise infrastructure consists mainly of workstations; therefore, only infrastructure services are available to companies in this group, which can be provided through a desktop operating system or services from cloud service providers.

Cloud services are fully available but given that companies in this group have low levels of digital skills, SaaS-type solutions are mainly used. Cloud services are available to the company's users through the Internet. All resources are hosted in the cloud provider's data centre.

All organisations that do not qualify for Groups 2, 3, 4 or 5 shall be members of this group. These companies are advised to carry out migration to classification groups 2 or 3 .

\section{B. Group-Disciple Use of ICT}

Possible job scenarios do not include regular computer use. The company has an independent Internet connection. The group is characterised by regular software and operating system renewal and overall maintenance. Organisation's computers have organised user authorization. Users use strict passwords. The company works with fee applications or purchase licenses. The company foresees a specific application software for relevant business processes. Companies in this group are characterised using an individual computer. The company does not organise network access control and network access rights. The company does not have sufficient infrastructure to maintain the application platform. SaaS-type cloud services may be in use. The company has a business card type home page or profile on social networks. Employees have a low level of digital skills. IT duties may be carried out by the company's employees or an outsourcing provider.

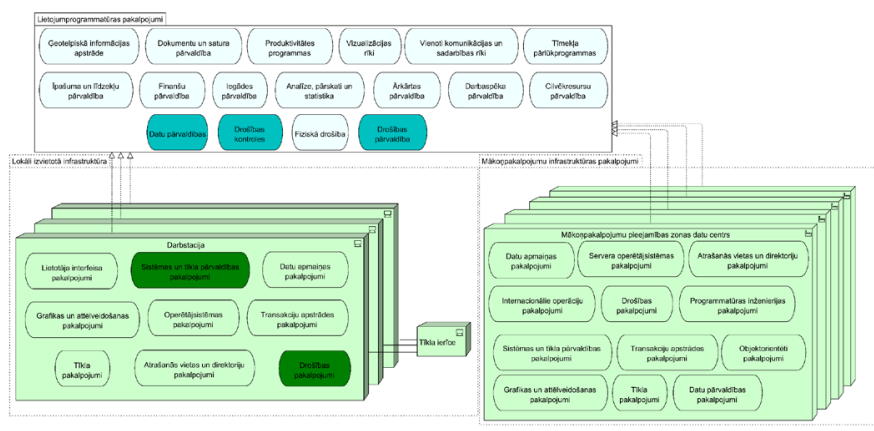

Fig. 3. Application and technology architecture viewpoint of Group B. Application service and technology service taxonomies are based on FEAF and TA TRM.

This view (see Fig. 3) involves the use of the following software services: geospatial information processing, document and content management, productivity applications, visualization tools, common communication and cooperation tools, web browsers, management of property assets, financial management, purchase management, analysis, reporting and statistics, emergency management, labour management, human resources management, physical security and data management.

Infrastructure services use services such as: operating system services, data exchange services, network services, user interface services, graphics and imaging services, location and directory services, systems and network management services, security services.

The enterprise infrastructure consists mainly of workstations; therefore, only infrastructure services are available to companies in this group, which can be provided through a desktop operating system or services from cloud service providers. 
Cloud services are fully available but given that companies in this group have a low level of digital skills, SaaS-type solutions are mainly used. Cloud services are available to the company's users through the Internet. All resources are hosted in the cloud provider's data centre.

All organisations which for some reason do not qualify for Groups 3, 4 or 5 should be members of this group. These companies are advised to carry out migration to classification groups 3 or 4 .

\section{Group-Defined Standards}

The company has an independent Internet connection. Computers are connected to the network. The group is characterised by regular software and operating system renewal and overall maintenance. The company organises the control of user rights. Control of network access is ensured. Users use strict passwords. The company works with freeware software or purchases licenses. The company foresees specific application usage for relevant business processes. Companies in this group are characterised by the shared use of applications. People can work together using applications hosted on the network. Computer is used for manual and automated tasks. The company has sufficient infrastructure to maintain the application platform. Cloud services of type IaaS, PaaS, SaaS may be used. The company has a business card type home page or profile on social networks. Training in ICT use and performance of job responsibilities is provided to the employees of the company. Employees may be able to work from home.

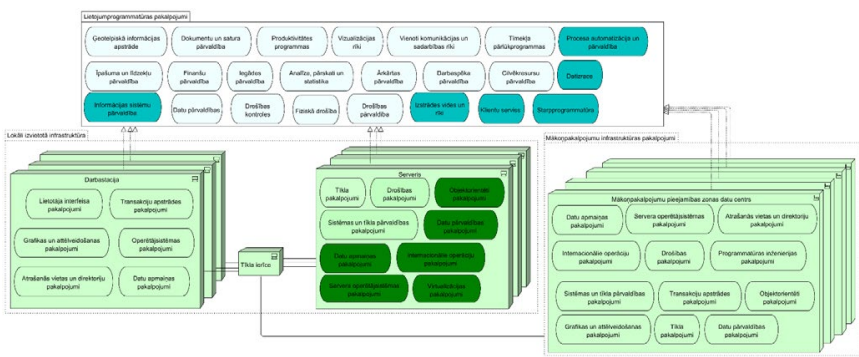

Fig. 4. Application and technology architecture viewpoint of Group C. Application service and technology service taxonomies are based on FEAF and TA TRM.

This view (see Fig. 4) involves the use of the following software services: geospatial information processing, document and content management, productivity software, visualization tools, common communication and cooperation tools, web browsers, management of property assets, financial management, purchase management, analysis, reporting and statistics, emergency management, labour management, human resources management, physical security, data management, process automation and management, data mining, middleware, customer service, development environments and tools, information system management.

Infrastructure services use services such as: operating system services, data exchange services, network services, user interface services, graphics and imaging services, location and directory services, systems and network management services, security services, object-oriented services, data management services, international operations services, virtualization services, data exchange services and server operating system services.

The enterprise infrastructure consists of workstations and servers, so all possible local infrastructure services are available to the companies of this group. Available cloud services can replace any local infrastructure service or service group.

Cloud services, including private, public, hybrid, IaaS, PaaS and SaaS solutions, are fully available and can be used for the benefit of the company, taking into consideration the technological maturity of the company. Resources are hosted in the local office on servers and/or in cloud service provider data centres.

The minimum requirements of this group is the ability to fully maintain the existing IT infrastructure, including the management of user rights, the existence of network access controls, group policies and documentation of all important business processes. If one of the above conditions is not fulfilled, the company is classified as a member of Group 2 or Group 1. All organisations which, for some reason, do not qualify for Group 4 or Group 5 should be the members of this group. These companies are advised to carry out migration to classification groups 4 or 5 .

\section{Group-Managed Prerequisites}

Organisations that have home pages provide a two-way flow of information. The home page must provide the ability to receive an immediate response to structured queries, such as a user-selected, product-specific configuration offer. Another option would be to provide personalised information to registered visitors. This type of home page can be hosted by an internet service provider. This requires a web server and highspeed Internet connection. ITSM, CM tools are in place to allow IT service activities to be evaluated. The companies in this group provide customers and partners with the possibility of purchasing goods or services via the homepage.

The organisation uses unified software that supports a variety of business processes, such as purchase, sale, accounting, production, etc., thereby promoting the sharing of information within the company.

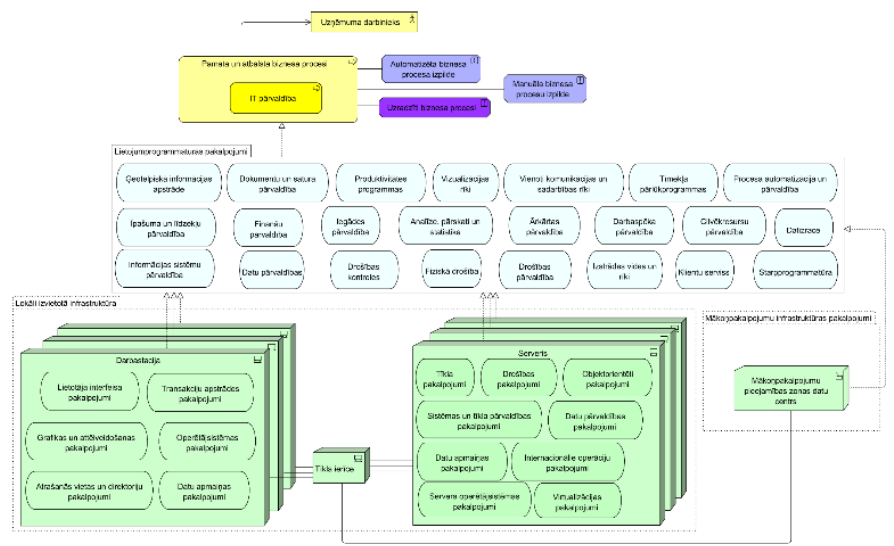

Fig. 5. Application and technology architecture viewpoint of Group D. Application service and technology service taxonomies are based on FEAF and TA TRM. 
This view (see Fig. 5) involves the use of the following software services: geospatial information processing, document and content management, productivity software, visualization tools, common communication and cooperation tools, web browsers, management of property assets, financial management, purchase management, analysis, reporting and statistics, emergency management, labour management, human resources management, physical security, data management, process automation and management, data mining, middleware, customer service, development environments and tools, and information system management.

Infrastructure services use services such as: operating system services, data exchange services, network services, user interface services, graphics and imaging services, location and directory services, systems and network management services, security services, object-oriented services, data management services, international operations services, virtualization services, data exchange services, server operating system services.

View implements a new business principle. The principle requires that business processes are monitored, and IT management is one of the most important business processes.

The minimum requirements of this group are performance and quality standards assessed for all important activities in all services. Organisation-wide process database is used to collect, store and analyse service information. Quantitative measurement is available to evaluate business processes and services.

If one of the above conditions is not fulfilled, the company classified is as a member of Group 3,2 or 1. All organisations which, for some reason, do not qualify for Group 5 should be the members of this group. These companies are advised to carry out migration to classification group 5.

\section{E. Group-Continuous Improvement}

The organisation provides a secure network and web server that support financial transactions and the processing of payment data. The organisation shall ensure that all business processes information is stored. The company complies with relevant global, regional, national and industry safety standards and recommendations.

Companies of this group apply big data analysis and use analytical information to redefine the scope of the business.

Companies of this group offer partners and customers electronic invoices that can be electronically processed.

This view (see Fig. 6) involves the use of the following software services: geospatial information processing, document and content management, productivity software, visualization tools, common communication and cooperation tools, web browsers, management of property assets, financial management, purchase management, analysis, reporting and statistics, emergency management, labour management, human resources management, physical security, data management, process automation and management, data mining, middleware, customer service, development environments and tools, and information system management.

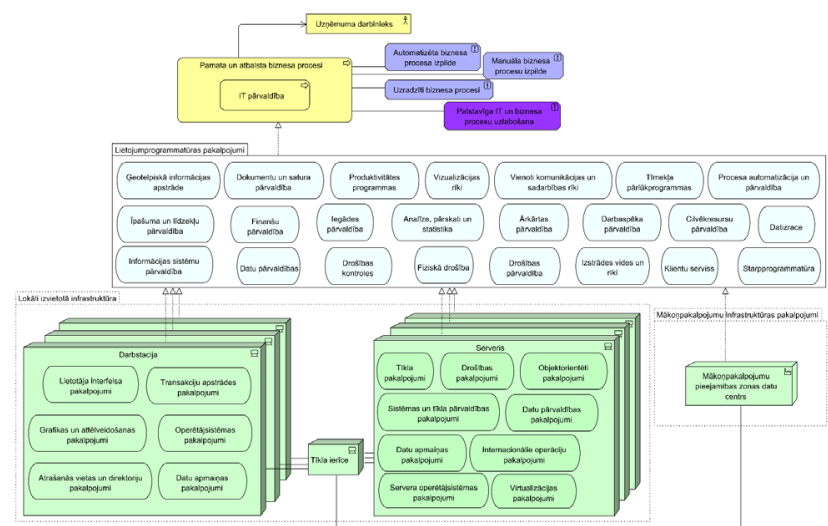

Fig. 6. Application and technology architecture viewpoint of Group E. Application service and technology service taxonomies are based on FEAF and TA TRM.

Infrastructure services use services such as: operating system services, data exchange services, network services, user interface services, graphics and imaging services, location and directory services, systems and network management services, security services, object-oriented services, data management services, international operations services, virtualization services, data exchange services, server operating system services.

The minimum requirements of this group are a focus on continuous improvement of processes. The company complies with various national, industrial, international and security standards. If one of the above conditions is not fulfilled, the company is classified as a member of Group 4, 3, 2 or 1. For the companies of this group, the strategy developed by the authors gives an insight into EA building blocks and their practical application in the EA change management approach, if not in use. Given the diversity of change management standards, this can be helpful for improving an existing approach. Within the scope of this study, the strategy does not provide vertical development scenarios for the members of this group. The strategy creates an opportunity for further research and development to improve it. The strategy may be complemented by technological solutions that may be useful for one of the groups.

\section{CONCLUSION}

The aim of the research has been to develop a strategy for the deployment of cloud services. Latvian SMEs are characterised by different degrees of ICT and IT infrastructure complexity. SMEs have been grouped according to the ICT used. The grouping is based on the classification proposed by the authors. The classification consists of five groups, which unite companies with similar infrastructures and offer improvement scenarios. After choosing a scenario, entrepreneurs may use TOGAD ADM as a change management model and architectural viewpoints as a reference model. Viewpoints have been based on EA standard and can therefore be re-used and improved in case of necessity. Architectural building blocks, including architectural viewpoints, allow understanding, learning and adopting technological concepts quickly. Building blocks provide a reduction in the time needed for EA development, which is one of the most important factors influencing SME ICT deployment. 


\section{REFERENCES}

L. Bassi, "Industry 4.0: Hope, hype or revolution?," RTSI 2017 IEEE 3rd Int. Forum Res. Technol. Soc. Ind. Conf. Proc., 2017. https://doi.org/10.1109/rtsi.2017.8065927

OECD, “OECD Economic Surveys Latvia,” 2019.

https://doi.org/10.1787/888933925844

[3] Central Statistical Bureau of Latvia, "Science and ICT." Available: http://data1.csb.gov.lv/pxweb/en/zin/ (accessed Oct. 31, 2020).

[4] P. Andries and U. Stephan, "Environmental innovation and firm performance: How firm size and motives matter," Sustain., vol. 11, no. 13, pp. 1-17, 2019. https://doi.org/10.3390/su11133585

[5] M. Khanna, "Non-Mandatory Approaches to Environmental Protection," J. Econ. Surv., vol. 15, no. 3, pp. 291-324, Jul. 2001. https://doi.org/10.1111/1467-6419.00141

[6] G. X. Tang, K. Park, A. Agarwal, and F. Liu, "Impact of innovation culture, organization size and technological capability on the performance of SMEs: The case of China," Sustain., vol. 12, no. 4, 2020. https://doi.org/10.3390/su12041355

[7] G. Harindranath, R. Dyerson, and D. Barnes, "ICT Adoption and Use in UK SMEs: a Failure of Initiatives?," Electron. J. Inf. Syst. Eval., vol. 11, no. 2, pp. 91-96, 2008.

[8] A. Khajeh-Hosseini, et al. "Decision Support Tools for Cloud Migration in the Enterprise ," 2011 IEEE 4th International Conference on Cloud Computing, 2011

https://doi.org/10.1109/cloud.2011.59

[9] R. Seethamraju, "Adoption of Software as a Service (SaaS) Enterprise Resource Planning (ERP) Systems in Small and Medium Sized Enterprises (SMEs)," Inf. Syst. Front., vol. 17, no. 3, pp. 475492, 2015. https://doi.org/10.1007/s10796-014-9506-5

[10] S. C. Satapathy, J. K. Mandal, S. K. Udgata, and V. Bhateja, Erratum to: Information Systems Design and Intelligent Applications, vol. 2, 2016. https://doi.org/10.1007/978-81-322$\underline{2755-7}$

[11] A. Bayaga and S. Flowerday, "Principal causes of information communication technology (ICT) risk failure in an SME," Proc. 2012 ASE Int. Conf. Cyber Secur. CyberSecurity 2012, no. SocialInformatics, pp. 152-156, 2012

https://doi.org/10.1109/cybersecurity.2012.26

[12] B. Briggs and E. Kassner, "Enterprise Cloud Strategy," (2nd ed.). Microsoft Press, 156 p., 2017, [Online]. Available: http://aka.ms/tellpress

[13] S. Laan, It Infrastructure Architecture - Infrastructure Building Blocks and Concepts Second Edition. Lulu Press Inc., 2017.

[14] N. Milanovic, Non-functional properties in service oriented architecture: Requirements, models and methods. IGI Global, 2011. https://doi.org/10.4018/978-1-60566-794-2

[15] R. Gruia-Catalin, "A Taxonomy of Current Issues in Requirements Engineering," Washington University, St. Lolis, 1985. Available: https://ieeexplore-ieee-

org.resursi.rtu.lv/stamp/stamp.jsp?tp=\&arnumber $=1662861$ (accessed May 03, 2020).

[16] N. M. S. Iswari, E. K. Budiardjo, and Z. A. Hasibuan, "Integrated ebusiness system architecture for small and medium enterprises," ACM Int. Conf. Proceeding Ser., pp. 240-243, 2019.

[17] D. Kargatzis, S. Sotiriadis, and E. G. M. Petrakis, "Virtual machine migration in heterogeneous clouds: From openstack to VMWare," 2017 IEEE 38th Sarnoff Symp., 2017.

https://doi.org/10.1109/SARNOF.2017.8080393

[18] O. Sefraoui, M. Aissaoui, and M. Eleuldj, "Cloud computing migration and IT resources rationalization," Int. Conf. Multimed. Comput. Syst. -Proceedings, pp. 1164-1168, 2014. https://doi.org/10.1109/ICMCS.2014.6911300

[19] J. Narantuya, H. Zang, and H. Lim, "Automated cloud migration based on network traffic dependencies," 2017 IEEE Conf. Netw. Softwarization Softwarization Sustain. a Hyper-Connected World en Route to 5G, NetSoft 2017, 2017. https://doi.org/10.1109/NETSOFT.2017.8004235

[20] P. Jamshidi, A. Ahmad, and C. Pahl, "Cloud Migration Research: A Systematic Review," IEEE Trans. Cloud Comput., vol. 1, no. 2, pp. 142-157, 2013. https://doi.org/10.1109/TCC.2013.10

[21] M. Villari, W. Zimmermann, and K.-K. Lau, Eds., Service-Oriented and Cloud Computing, vol. 8745. Berlin, Heidelberg: Springer Berlin Heidelberg, 2014.
[22] C. Lin, H. Sun, J. Hwang, M. Vukovic, and J. Rofrano, "Cloud readiness planning tool (CRPT): An AI-based framework to automate migration planning," IEEE Int. Conf. Cloud Comput. CLOUD, vol. 2019, pp. 58-62, 2019.

https://doi.org/10.1109/CLOUD.2019.00021

[23] P. V. Beserra, A. Camara, R. Ximenes, A. B. Albuquerque, and N. C. Mendonça, "Cloudstep: A step-by-step decision process to support legacy application migration to the cloud," 2012 IEEE 6th Int. Work. Maint. Evol. Serv. Cloud-Based Syst. MESOCA 2012, pp. 7-16, 2012. https://doi.org/10.1109/MESOCA.2012.6392602

[24] R. Talwadker and C. George, "Yodea: Workload pattern assessment tool for cloud migration," Proc. Int. Conf. Cloud Comput. Technol. Sci. CloudCom, dec. 2018, pp. 17-20, 2018. https://doi.org/10.1109/CloudCom2018.2018.00019

[25] M. Vukovic and J. Hwang, "Cloud migration using automated planning," Proc. NOMS 2016 - 2016 IEEE/IFIP Netw. Oper. Manag. Symp., pp. 96-103, 2016.

https://doi.org/10.1109/NOMS.2016.7502801

[26] S. Kewei, L. Ying, L. Jing, X. Xiang, and Q. Quan, "Network traffic-based automatic optimized migration from physical to virtualized cloud environment with UCM tool," Proc. 2009 2nd IEEE Int. Conf. Broadband Netw. Multimed. Technol. IEEE IC BNMT2009, pp. 281-285, 2009. https://doi.org/10.1109/ICBNMT.2009.5348483

[27] S. K. Majhi and S. K. Dhal, "A security context migration framework for Virtual Machine migration," 2015 Int. Conf. Comput. Netw. Commun. CoCoNet 2015, pp. 452-456, 2016.

https://doi.org/10.1109/CoCoNet.2015.7411225

[28] H. Liang, H. Dai, X. Pei, and Q. Zhang, "A new pre-copy strategy for live migration of virtual machines," Proc. - 2016 Int. Conf. Identification, Inf. Knowl. Internet Things, IIKI 2016, vol. 2018, pp. 54-59, 2018. https://doi.org/10.1109/IIKI.2016.45

[29] F. L. Leite et al., "Migratool: Towards a web-based spatial database migration tool," Proc. - Int. Work. Database Expert Syst. Appl. DEXA, vol. 2006, pp. 480-484, 2005.

https://doi.org/10.1109/DEXA.2005.132

[30] N. Dino, A. Dico, and D. Midekso, "A new way of architecting the enterprise," Proc. Int. Conf. Manag. Emergent Digit. Ecosyst. MEDES 2012, pp. 48-52, 2012. https://doi.org/10.1145/2457276.2457286

[31] A. Sun, J. Zhou, T. Ji, and Q. Yue, "CSB: Cloud service bus based public SaaS platform for small and median enterprises," Proc. 2011 Int. Conf. Cloud Serv. Comput. CSC 2011, pp. 309-314, 2011. https://doi.org/10.1109/CSC.2011.6138539

[32] N. Ford, R. Parsons and P. Kua, Building evolutionary architectures. O'Reilly Media Inc, 2017

[33] R. E. Sward and K. J. Whitacre, "A multi-language service-oriented architecture using an enterprise service bus," Proc. ACM SIGAda Annu. Int. Conf. SIGAda, pp. 85-89, 2008. https://doi.org/10.1145/1454474.1454489

[34] P. Patrick, "Impact of SOA on enterprise information architectures," Proc. ACM SIGMOD Int. Conf. Manag. Data, vol. 1, no. 781, pp. 844-848, 2005. https://doi.org/10.1145/1066157.1066263

[35] S. Buckl, F. Matthes, I. Monahov, S. Roth, C. Schulz, and C. M. Schweda, "Enterprise Architecture Management Patterns for Company-wide Access Views on Business Objects," in Proceedings of the 16th European Conference on Pattern Languages of Programs - EuroPLoP'11, Irsee Monastery, Bavaria, Germany, vol. 2, no. 3, pp. 1-12, 2011. https://doi.org/10.1145/2396716.2396727

[36] J. Hafner, S. Schwingel, T. Ayers, and R. McLaughlin, "Azure Strategy and Implementation Guide," p. 122, 2018, [Online]. Available: http://www.microsoft.com.

[37] A. Hol and A. Ginige, "Bridging the Gaps between eTransforming SMEs and SME - ICT Providers." In: Cellary W., Estevez E. (eds) Software Services for e-World. I3E 2010. IFIP Advances in Information and Communication Technology, vol 341. Springer, Berlin, Heidelberg, pp. 61-69, 2010. https://doi.org/10.1007/978-3642-16283-1 10

[38] "Software Applications: Concepts, Methodologies, Tools, and Applications ... - Google Books."

https://books.google.lv/books?id= SklFgSidxQC\&pg=PR5-

IA3\&lpg=PR5-IA3\&dq=Carl-

Fredrik+Sørensen+Norwegian+University+of+Science + and + Techn ology,+ Norway $\% 5 \mathrm{D},+\% 5$ BChapter $+6.6+$ Becoming $+a+$ Learning $+\mathrm{O}$ 
rganization+in+the+Software+Industry: + Is + CMM + the + Silver+Bull et?\&source $=$ bl\&ots $=$ BCAvG8AB9q\&sig=ACfU3U2SOZXYesTmk yQE9x3wrt3ndKeJ9g\&hl=en\&sa=X\&ved=2ahUKEwictviLhJvpAh VQXpoKHX4GAT8Q6AEwAHoECAoQAQ\#v=onepage\&q\&f=fal se (accessed May 04, 2020).

[39] "Strategies for Growth in SMEs : The Role of Information and Information Systems."

http://web.a.ebscohost.com.resursi.rtu.lv/ehost/ebookviewer/ebook/ ZTAwMHh3d19fMTIzNDI3X19BTg2?sid=9e0fd99b-6b2c-46e1acb7-e03adf9352ef@sdc-v-sessmgr01\&vid=3\&format=EB\&rid=1 (accessed May 03, 2020).

[40] A. Ginige, S. Murugesan, and P. Kazanis, "A Road Map for Successfully Transforming SMEs into E-Businesses," vol. 14, pp. 39-51, May 2001.

[41] J. Yang, A. Ginige, H. C. Mayr, and R.-D. Kutsche, Eds., Information Systems: Modeling, Development, and Integration. Springer-Verlag, Berlin, Heidelberg, 2009. https://doi.org/10.1007/978-3-642-01112-2

[42] D. Radovanović, D. Lučić, T. Radojević, and M. Šarac, "Information technology governance - COBIT model," Proceedings MIPRO 2011, May 23-27, Opatija, Croatia, 2011.

[43] I. H. A. Wahab and A. Arief, "An integrative framework of COBIT and TOGAF for designing IT governance in local government," Proceedings of ICITACEE 2015 - 2nd International Conference on Information Technology, Computer, and Electrical Engineering Green Technology Strengthening in Information Technology, Electrical and Computer Engineering Implementation, Mar. 2016 pp. 36-40. https://doi.org/10.1109/ICITACEE.2015.7437766

[44] S. Sahibudin, M. Sharifi, and M. Ayat, "Combining ITIL, COBIT and ISO/IEC 27002 in order to design a comprehensive IT framework in organizations," Proc. - 2nd Asia Int. Conf. Model. Simulation, AMS 2008, pp. 749-753, 2008. https://doi.org/10.1109/AMS.2008.145

[45] V. Chiprianov, Y. Kermarrec, and S. Rouvrais, "Extending enterprise architecture modeling languages: Application to telecommunications service creation," Proc. $27^{\text {th }}$ Annual ACM Symp. Appl. Comput., pp. 1661-1666, 2012. https://doi.org/10.1145/2245276.2232044

[46] "ISO - ISO/IEC/IEEE 42010:2011 - Systems and software engineering - Architecture description," 2017.

https://www.iso.org/standard/50508.html (accessed May 16, 2020).

[47] S. Birudavolu and B. Nag, Business Innovation and ICT Strategies. Palgrave Macmillan, Singapore, 2019. https://doi.org/10.1007/978981-13-1675-3

[48] C. Armstrong et al., "Using the Archimate Language with UML," Open Gr., p. 38, 2013.

[49] K. Hinkelmann, "Enterprise Architecture Views and Viewpoints in ArchiMate," pp. 1-44, 2012, [Online]. Available: http://knut.hinkelmann.ch/lectures/EA2012/EA_3c_Views_Viewpoi nts.pdf.
Dmitrijs Bolozdina, M. sc. ing., former student of the Master study programme at the Institute of Information Technology, RTU. He is a Certified Microsoft Intune and Endpoint Manager Administrator. He works as an IT Operations Architect at ATEA Global Services. Professional interests include cloud management solutions and project management.

E-Mail: Dmitrijs.bolozdina@outlook.com

Rūta Pirta-Dreimane, Dr. sc. ing., has more than 13 years of experience in the IT industry. She has participated in more than 80 different IT projects. Rūta Pirta-Dreimane has received a Doctoral degree in Information Technology from Riga Technical University. During the period from 2011 to 2018, Rūta worked in management consulting at PricewaterhouseCoopers. Since 2016, Rūta PirtaDreimane has been a Researcher and Assistant Professor at Riga Technical University. Currently Rūta Pirta-Dreimane is working as an Enterprise Architect at an international financial institution and continues to work at Riga Technical University. She specialises in the development of IT and enterprise architecture, IT strategy planning, IT control audits and information security. E-Mail: ruta.pirta@rtu.lv

Andrejs Romānovs, Dr. sc. ing., Associate Professor and Senior Researcher at the Institute of Information Technology, as well as the Head of Department of Modelling and Simulation at Riga Technical University (Latvia). He has 20 years of academic experience and over 30 years of professional experience in developing $50+$ information systems for state and private businesses worldwide. His professional interests include modelling of MIS, cybersecurity, blockchain, IT governance, risk management, integrated IT in health care, logistics and supply chain management, e-commerce, as well as education in these areas. He is an expert in IT of the Latvian Council of Science, member of the ISACA and LSS, senior member of IEEE, chair of IEEE MRR Committee, chair of Latvia Blockchain Group. He is the author of 100+ textbooks and papers in scientific journals and conference proceedings in the field of information technology. He organised and participated in over 50 international scientific conferences, as well as in numerous national and EU scientific and $\mathrm{R} \& \mathrm{D}$ projects.

E-Mail: Andrejs.Romanovs@rtu.lv

ORCID iD: https://orcid.org/0000-0003-1645-2741 